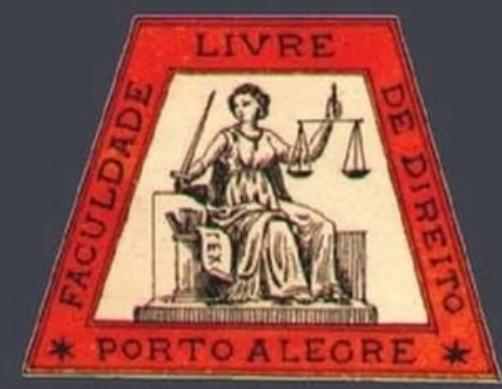

\title{
A contrarreforma trabalhista e o trabalho intermitente
}

\author{
Antireform of Labor Law and the intermittent work
}

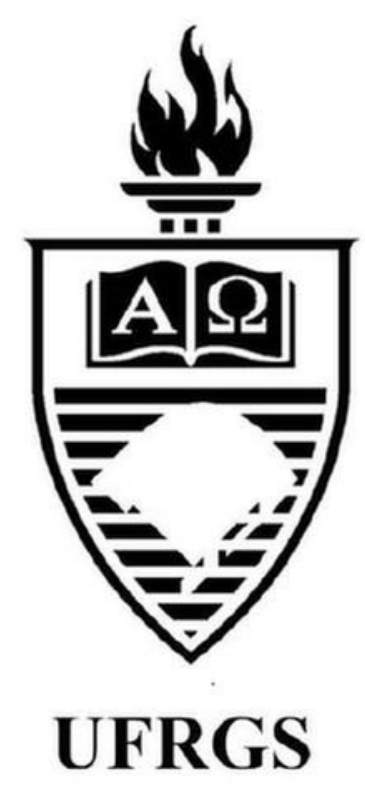

Marcos Paulo da Silva Oliveira Pontifícia Universidade Católica de Minas Gerais

\section{Maria Cecília Máximo Teodoro}

Pontifícia Universidade Católica de Minas Gerais 


\title{
A contrarreforma trabalhista e o trabalho intermitente
}

\author{
Antireform of Labor Law and the intermittent work
}

\author{
Marcos Paulo da Silva Oliveira*
}

Maria Cecília Máximo Teodoro**

\section{REFERÊNCIA}

OLIVEIRA, Marcos Paulo da Silva; TEODORO, Maria Cecília Máximo. A contrarreforma trabalhista e o trabalho intermitente. Revista da Faculdade de Direito da UFRGS, Porto Alegre, n. 39, vol. esp., p. 175-191, dez. 2018.

\section{RESUMO}

O objetivo central deste artigo é investigar o contrato de trabalho intermitente, institucionalizado a partir da Lei 13.467 de 2017 que ensejou a reforma trabalhista brasileira. Trata-se uma nova modalidade de contratação, desconhecida no Brasil, mas que já vinha sendo difundida em muitas legislações ao longo do globo e ficou conhecida como o contrato de trabalho "zero hora". Por esta modalidade enquadra-se a prestação de serviços subordinada, mas não contínua, que ocorre com alternância de períodos de execução de serviços e de inatividade e que no Brasil poderá ser realizada independentemente do tipo de atividade do empregado e do empregador, o que tende a facilitar sua generalização. Destarte, se vislumbra conhecer e interpretar criticamente esse novo formato de contratação pelo método jurídico-sociológico, buscando entender os impactos jurídicos, sociais e econômicos dele advindos, sobretudo na tentativa de verificar as possibilidades de adequação desse tipo de contrato às bases principiológicas do Direito do Trabalho e às novas conformações de trabalho experimentadas nos últimos anos. Tenta-se na presente investigação empreender verdadeira trincheira hermenêutica em prol de uma contrarreforma, objetivando engendrar práticas laborais juridicamente sustentáveis. Em conclusão, aventa-se a possibilidade de incidência desse contrato ao modelo Uber de serviços, destacando-se a importância desse exercício hermenêutico de resistência, a fim de que a reforma trabalhista seja palco de novas possibilidades de proteção dos trabalhadores.

\section{PALAVRAS-CHAVE}

Trabalho Intermitente. Reforma Trabalhista. Uber.

\section{ABSTRACT}

The main objective of this paper is to investigate the intermittent work contract, institutionalized in the Act 13.467 of 2017 that led to the Brazilian labor reform. This is a new modality of hiring, unknown not Brazil, but it is already being spread in many acts throughout the globe and became known as the "zero hour" work contract. This modality includes the provision of subordinate services, but not continuous, which occurs with the alternation of periods of service execution and inactivity, and that in Brazil will be performed independently of the type of activity of the employee and the employer, which tends to facilitate its generalization. Therefore, it is envisaged to know and interpret critically this new format of contracting by the legal-sociological method, seeking to understand the legal, social and economic impacts of it, especially in the attempt to verify the possibilities of adequacy of this type of contract to the foundational bases of the Labor Law and the new working scenario experienced in recent years. In the present investigation it is attempted to embark on a true hermeneutic trench in favor of a counter-reform, with the aim of produce legally sustainable labor practices. In conclusion, it's rising the possibility of incidence of this contract made like the Uber model of services, highlighting the importance of this hermeneutic exercise of resistance, so that the labor reform can be an arena of new possibilities of protection of workers.

\section{KEYWORDS}

Intermittent Work. Labor Reform. Uber.

\footnotetext{
* Mestrando em Direito do Trabalho pelo Programa de Pós-Graduação em Direito da PUC-MG. Pesquisador bolsista CAPES. Graduado em Direito pela PUC-MG.

*** Professora de Direito do Trabalho do Programa de Pós-Graduação em Direito e da Graduação da PUC-MG. Professora Convidada do Mestrado em Direito do Trabalho da Universidade Externado da Colômbia. Pós-Doutora em Direito do Trabalho pela Universidade de Castilla-La Mancha, Espanha, com bolsa de pesquisa da CAPES. Doutora em Direito do Trabalho e da Seguridade Social pela USP. Mestre em Direito do Trabalho pela PUC-MG. Professora de Direito do Trabalho do Programa de Pós-Graduação em Direito e da Graduação da PUC-MG. Professora Convidada do Mestrado em Direito do Trabalho da Universidade Externado da Colômbia.
} 


\section{SUMÁRIO}

Introdução. 1. A lei 13.467 e a institucionalização da precariedade: aspectos gerais. 2. O contrato de trabalho intermitente.

3. Aspectos sociais do trabalho intermitente: vidas zero hora. 4. O caso Uber e a contrarreforma: desafios e possibilidades.

Conclusão. Referências.

\section{INTRODUÇÃO}

No presente artigo, tendo em vista a abordagem interdisciplinar que as reformas do Direito do Trabalho merecem, se optou pelo método jurídico-sociológico de análise. Assim, no primeiro capítulo será lançado olhar sobre os aspectos gerais da reforma trabalhista advinda da Lei 13.467 de 13 de julho de 2017, buscando-se traçar um panorama geral das mudanças perpetradas e dos novos institutos criados. Nesse momento desvenda-se que a partir de uma leitura constitucional eles pouco coadunam com a proteção trabalhista pretendida pela Constituição Federal. Na verdade, a nova legislação do trabalho trazida à análise acaba por se revelar como uma clara tentativa de institucionalização e generalização de formas precárias de emprego, e por isso vão de encontro a todo o arcabouço justrabalhista brasileiro consolidado nas últimas décadas.

No segundo capítulo, o contrato de trabalho intermitente torna-se o grande objeto de investigação. Nesse capítulo serão analisados os requisitos formais exigidos pela legislação trabalhista para a conformação desse tipo de contrato, destacando-se as zonas de proximidade e afastamento da nova lei brasileira em comparação a algumas legislações internacionais, bem como se verificando as lacunas e contradições existentes nos dispositivos que agora passam a disciplinar o contrato intermitente no Brasil.

Após minucioso estudo sobre os aspectos legislativos do contrato de trabalho intermitente, no terceiro capítulo será lançado olhar para os aspectos sociais inerentes a esse tipo de contrato.
Serão destacadas as sequelas sociais ocasionadas por contratos cada vez mais instáveis e em que medida a contratação de trabalho "zero hora" culmina em vidas humanas igualmente "zero hora", sem quaisquer possibilidades de projetos futuros. É que nessa modalidade de contratação, intermitente, o trabalhador é lançado a uma vida de incertezas e inseguranças, já que acaba por assumir grande parte dos riscos do empreendimento.

No quarto capítulo, busca-se empreender um amplo exercício investigativo para uma filtragem humanizada desse novo modelo de contratação. Nesse momento tem-se como objeto de análise o modelo Uber de serviços e negócios, aventando-se a possibilidade de que a contratação intermitente seja utilizada para regularizar a prestação de serviços entre os motoristas e a plataforma digital.

Em sede de conclusão, destaca-se a importância de um exercício hermenêutico de resistência, para que a reforma trabalhista empreendida pela Lei 13.467 seja aventada como um palco de novas possibilidades de proteção da classe trabalhadora, longe da precariedade que ela inicialmente aparenta intentar, reforçando-se a necessidade de que todos os dispositivos desta nova lei sejam interpretados e aplicados em harmonia e respeitando a principiologia trabalhista e as proteções constitucionais dos trabalhadores. 


\section{1 \\ A \\ LEI \\ 13.467 \\ $\mathbf{E}$ \\ INSTITUCIONALIZAÇÃOO PRECARIEDADE: ASPECTOS GERAIS}

A análise da nova legislação trabalhista demanda olhar cauteloso. Instituída a partir da lei 13.467 de 13 de julho de 2017, a reforma trabalhista altera drasticamente a Consolidação das Leis do Trabalho (CLT), e as Leis 6.019, de 3 de janeiro de 1974, 8.036, de 11 de maio de 1990, e 8.212, de 24 de julho de 1991, tendo como hipotético fundamento adequar a legislação às novas relações de trabalho, modernizando-a.

Apesar de sua suposta intencionalidade, nesse discurso de modernização nota-se pouco de verdade e muita ideologia. Tornando-se possível perceber que a referida reforma parece contrariar múltiplos princípios jurídicos constitucionais trabalhistas. E lado outro, em verdade busca incessantemente atender aos ditames empresariais típicos da era da flexibilidade, desconsiderando a pessoa humana que trabalha.

Para Jorge Luiz Souto Maior:

Essa 'reforma', vale repetir, não é meramente uma adaptação aos ditos 'novos tempos'. Trata-se, em verdade, de uma alteração profunda da correlação entre o capital e o trabalho no Brasil, modificando mais de 200 comandos regulatórios, sendo que todos, precisamente todos, atendem aos interesses econômicos, o que fere, explicitamente, o pacto internacional da regulação trabalhista, o ajuste constitucional nacional e a tradição jurídica trabalhista, assim como a diversos preceitos ligados aos Direitos Humanos (SOUTO MAIOR, 2017, p. 187).

O atual cenário de profundas transformações no Direito do Trabalho brasileiro, por meio da reforma trabalhista, tem tornado cada vez mais perceptível a adaptação das relações laborais aos moldes precarizados impostos pelo sistema capitalista neoliberal. Tudo isso sob o desígnio de proporcionar pujança econômica e uma maior empregabilidade.

Como será visto ao longo do presente estudo, essa adaptação tem culminado em diversas fraturas na vida da pessoa que trabalha, sejam em suas relações afetivas, políticas e familiares.

A nova dinâmica do trabalho associada aos constantes riscos e a iminente falta de controle acarretam impactos sobre a vida pessoal dos trabalhadores à medida que se perde a chance e a oportunidade de organização de vida e do futuro na era da flexibilidade:

\begin{abstract}
Essa ênfase na flexibilidade está mudando o próprio significado do trabalho, e também as palavras que empregamos para ele. 'Carreira', por exemplo, significava originalmente, na língua inglesa, uma estrada para carruagens, e, como acabou sendo aplicada ao trabalho, um canal para as atividades econômicas de alguém durante a vida inteira. $\mathrm{O}$ capitalismo flexível bloqueou a estrada reta da carreira, desviando de repente os empregados de um tipo de trabalho para outro. A palavra 'job' [serviço, emprego], em inglês do século quatorze, queria dizer um bloco ou parte de alguma coisa que se podia transportar numa carroça de um lado para o outro. A flexibilidade hoje traz de volta esse sentido arcano de job, na medida em que as pessoas fazem blocos, partes de trabalho, no curso de uma vida (SENNETT, 2014, p. 9).
\end{abstract}

Ilustrativamente, verifica-se que a Lei 13.467 de 13 de julho de 2017 programa institutos como o da quitação geral anual, no qual o trabalhador passa a ter a "faculdade" de dispor de seus direitos em prol do empregador, mediante a assinatura de um termo junto ao sindicato (Art. 507-B).

Também regulamenta o teletrabalho, mas ao invés de criar um ambiente saudável e de garantia de direitos, origina diversas problemáticas no tocante a assunção dos riscos do empreendimento por parte do trabalhador que nem ao menos terá direito a jornada (Art. 75-A e seguintes), bem como levanta discussões acerca da responsabilidade por acidentes de trabalho e doenças ocupacionais.

A reforma também generaliza formas de contratação a tempo parcial (Art. 58-A) - e com possibilidade de realização de horas extras - e não o bastante, traz ainda a retirada da contribuição 
sindical obrigatória, sem antes disso garantir o fomento a organização coletiva e sem coibir verdadeiramente as práticas antissindicais (Art. 579 e seguintes).

Também importa mencionar a criação do trabalho intermitente, objeto central do presente estudo e que será melhor examinado no capítulo seguinte. Nessa modalidade de contratação o trabalhador é completamente lançado a instabilidade e imprevisibilidade das variações do capitalismo especulativo.

Todos os ilustrativos institutos acima mencionados demonstram a ausência de diálogo com vários princípios justrabalhistas, e ao mesmo tempo comprovam que o discurso de modernização na verdade serve para mascarar a precarização típica da era flexível ${ }^{1}$. "Diz-se que, atacando a burocracia rígida e enfatizando o risco, a flexibilidade dá às pessoas mais liberdade para moldar suas vidas" (SENNETT, 2014, p. 10). Mas apesar disso, o que se tem visto não é mais liberdade, mas ao contrário, talvez até mesmo um aprisionamento do sujeito pelo trabalho. Diante do instável, sem qualquer projeto de longo prazo, a rede pode afrouxar os laços sociais, pois quando não há "longo prazo", se corrói a confiança, a lealdade e o compromisso mútuo (SENNETT, 2014).

Essas são algumas das sequelas sociais oriundas da disseminação de modelos flexíveis e pouco duráveis de trabalho, justamente como os que agora tenta generalizar a referida Lei 13.467.

Exatamente por isso parece que essa legislação tem clara tentativa de

\footnotetext{
${ }^{1}$ Para Jorge Luiz Souto Maior a reforma é vendida "como se fosse meramente uma necessária modernização da legislação trabalhista, para superar a CLT de 1943 (que nem existe mais), dinamizar a economia e conferir emprego para 14 milhões de desempregados. Mas essa fração da sociedade brasileira, que está controlando tal processo em acordo com os interesses do mercado financeiro e, mais propriamente, portanto, com o capital estrangeiro, tem atacado a legislação trabalhista desde quando ela começou a existir ainda no período da Primeira República. Essa legislação, ademais, vem sendo flexibilizada desde 1965 e
}

institucionalização

da precariedade, desconsiderando princípios basilares do Direito Laboral, como a proteção, alteridade, primazia da realidade sobre a forma, dentre outros. De toda forma, aqui se propõe conhecer especificamente o novel instituto criado pela reforma trabalhista, o contrato de trabalho intermitente, até mesmo para que se torne possível reconhecer os mecanismos jurídicos que possibilitam interpretá-lo de forma a harmonizá-lo com o ordenamento juslaboral.

\section{O CONTRATO DE TRABALHO INTERMITENTE}

O contrato de trabalho intermitente foi inaugurado na legislação trabalhista brasileira sob o véu da reforma de 2017. É que de acordo com a nova redação do Art. 443 da CLT, alterado pela Lei 13.467, o contrato individual de trabalho poderá ser acordado tácita ou expressamente, verbalmente ou por escrito, por prazo determinado ou indeterminado, ou ainda para prestação de trabalho intermitente.

Por sua vez, o parágrafo terceiro do referido artigo conceitua essa modalidade de contrato, explicitando que será considerado como intermitente o contrato de trabalho no qual a prestação de serviços, com subordinação, não é contínua, ocorrendo com alternância de períodos de prestação de serviços e de inatividade, determinados em horas, dias ou meses.

Como será visto a seguir, "o texto coloca o trabalhador intermitente numa posição ontológica

é, pode-se dizer sem receio, a mais desrespeitada do mundo, e tudo isso sem qualquer efeito benéfico para a economia nacional e a melhoria da condição social dos trabalhadores, o que revela que não é, propriamente, de modernização que falam, até porque inúmeras efetivas medidas modernizantes, como a redução da jornada e a eliminação da prática de horas extras, por exemplo, que representariam claras políticas públicas de geração de empregos e de diminuição dos custos sociais com acidentes do trabalho, sequer são postas em questão" (MAIOR, 2017, p. 184). 
de imprevisibilidade, mas mantém a essência da relação de emprego, sem alterar a redação do artigo $3^{\circ}$ da CLT. Concebe, assim, uma antinomia, porquanto ninguém pode 'ser e não ser' ao mesmo tempo" (HIGA, 2017, não paginado). É um contrato que altera significativamente o modo como têm sido pensados os cinco elementos fático-jurídicos da relação de emprego, sobretudo no que tange ao elemento da habitualidade ou não-eventualidade:

O contrato de trabalho intermitente abala os alicerces do Direito do Trabalho em vários aspectos. O primeiro advém do fato de os artigos $443, \S 3^{\circ}$ e 452 $\mathrm{B}$ obliterarem a habitualidade como elemento da relação de emprego. Isso porque 'independentemente da pessoalidade ou da subordinação, aquele que presta serviços em caráter eventual não é empregado. É, na realidade, por oposição à definição legal, um trabalhador eventual' (HIGA, 2017, não paginado).

O parágrafo terceiro do art. 443, com a nova redação dada pela Lei 13.467, ainda estabelece que a contratação do trabalho intermitente dar-seá independentemente do tipo de atividade do empregado e do empregador, exceto para os aeronautas, regidos por legislação própria. Nesse ponto, importa salientar que tal determinação não encontra correspondência em várias legislações internacionais, que apesar de igualmente instituírem o contrato de trabalho intermitente o restringiram as empresas que comprovadamente demandam esse tipo de serviço por desenvolverem atividades descontinuadas.

Exemplificativamente cita-se a legislação trabalhista portuguesa, Lei n. ${ }^{0} 7 / 2009$, que em sua subsecção III, mais precisamente nos artigos 157 a 160, institui o trabalho intermitente, mas restrito as empresas que exerçam atividade com descontinuidade ou intensidade variável. Nesse sentido, talvez até mesmo por isso tal modalidade de contrato não tenha se generalizado naquele país.

O modelo brasileiro, sobretudo por se descolar da obrigatoriedade de que as empresas que podem contratar trabalhadores intermitentes exerçam atividades comprovadamente descontinuadas, lança o trabalhador ainda mais em um campo de incerteza e imprevisibilidade e com isso parece intensificar a assunção dos riscos do empreendimento por parte do empregado, afastando-se completamente da observância do princípio da alteridade. Nas palavras de Flávio da Costa Higa:

Ao sujeitar a prestação de serviços à existência de
demanda, transfere-se parte do risco ao empregado,
o que exigirá imensa ginástica hermenêutica a fim de
contornar a erosão epistemológica advinda de um
apêndice travestido de contrato de emprego, a partir
da desfiguração dos sujeitos que compõem a relação
jurídica laboral (HIGA, 2017, não paginado).

Com relação aos requisitos formais dessa nova modalidade de contrato, os mesmos estão descritos no novo Art. 452-A.

Através desse dispositivo esclarece-se que o contrato de trabalho intermitente deve ser celebrado por escrito e deve conter especificamente o valor da hora de trabalho, que não pode ser inferior ao valor horário do salário mínimo ou àquele devido aos demais empregados do estabelecimento que exerçam a mesma função em contrato intermitente ou não.

Ou seja, por ser modalidade excepcional de contratação (lembre-se que o contrato por prazo indeterminado ainda e apesar de tudo deve continuar sendo a regra no Direito do Trabalho brasileiro), demanda a observância de todos esses requisitos formais por parte do empregador, sob pena de que o contrato intermitente seja descaracterizado e passe a ser considerado indeterminado, assim como hoje acontece com o 
contrato por prazo determinado, tendo em vista que o ônus da forma é do empregador ${ }^{2}$ :

A formalidade exigida pelo caput do art. 452-A da CLT é essencial para a validade da cláusula de "intermitência", o que significa que, se o empregado foi contratado oralmente ou de maneira tácita para trabalhar desta forma, não será regido pelo contrato intermitente e o seu tempo à disposição será contado conforme o art. $4^{\circ}$ da CLT, devendo ser aplicadas as demais regras da CLT (CASSAR, BORGES, 2017, p. 46).

Alguns outros requisitos passam a ser lançados nos parágrafos seguintes, os quais, por sua redação confusa tendem a suscitar diversos questionamentos.

O primeiro deles diz respeito ao critério temporal para convocação do empregado por parte do empregador. De acordo com o parágrafo primeiro do art. 452-A, o empregador convocará, por qualquer meio de comunicação eficaz, para a prestação de serviços, informando qual será a jornada, com, pelo menos, três dias corridos de antecedência. Por sua vez, o parágrafo segundo estabelece o prazo de aceite do trabalhador, que, recebida a convocação, terá o prazo de vinte e quatro horas para responder ao chamado, presumindo-se, no silêncio, a recusa.

Interessante notar que a lei traz um importante dispositivo acerca do aceite ou recusa da convocação, que mais adiante, como será visto, servirá para o teste da hipótese de que essa modalidade de contrato convirá para o enquadramento fático-jurídico dos trabalhadores de plataformas virtuais, tais quais os do modelo Uber de serviços.

É que o parágrafo terceiro estabelece que a recusa da oferta de trabalho por parte do empregado não descaracteriza a subordinação para fins do contrato de trabalho intermitente.

Por sua vez, o parágrafo quarto do mesmo dispositivo estabelece uma sanção pecuniária para

\footnotetext{
${ }^{2} \mathrm{O}$ ônus dessa formalidade decorre da interpretação do princípio da continuidade da relação de emprego, e de todo o arcabouço principiológico trabalhista, que impõe que os
}

a parte que descumprir o pactuado sem justo motivo. Isto é, tanto o empregado que aceitar o trabalho e não comparecer, quanto o empregador que convoca com a promessa de trabalho e não o fornece, sem justo motivo, pagará à outra parte, no prazo de trinta dias, multa de $50 \%$ (cinquenta por cento) da remuneração que seria devida, permitida a compensação em igual prazo.

Nesse momento surgem importantes dúvidas, tais quais apontam Vólia Bomfim Cassar e Leonardo Dias Borges:

\begin{abstract}
O valor da multa deve ser sobre todo o trabalho convocado ou apenas sobre o valor do salário do dia, da hora? Vamos dizer que o empregador convoque um professor intermitente para trabalhar naquele semestre, em substituição a outro. Caso aceite e não compareça, pagará pelo dia faltante ou por todo o semestre? (CASSAR, BORGES, 2017, p. 46).
\end{abstract}

De maneira bastante razoável esses autores (CASSAR, BORGES, 2017) sugerem que a multa incida unicamente sobre um dia de trabalho e não sobre o todo o período de convocação. Parece bastante razoável.

O parágrafo quinto do mencionado artigo aduz que o período de inatividade não seja considerado tempo à disposição do empregador, podendo o trabalhador prestar serviços a outros contratantes. Nesse ponto, importante comentar que a exclusividade nunca foi um elemento fáticojurídico da relação de emprego, logo, em nenhuma hipótese, caso o empregado preste serviço para dois ou mais empregadores distintos isso impactaria na conformação do vínculo de emprego.

Finalmente, o parágrafo sexto estabelece que ao final de cada período de prestação de serviço o empregado receberá o pagamento imediato das seguintes parcelas: I - remuneração; II - férias proporcionais com acréscimo de um terço; III - décimo terceiro salário proporcional; IV - repouso semanal remunerado; e V -

contratos de trabalho serão em regra por prazo indeterminado. 
adicionais legais. Nesse ponto, a dúvida que surge é qual o lapso temporal mínimo para o recebimento das parcelas acima discriminadas. Qual o período de prestação de serviços a ser considerado? O dia da prestação de serviço? O mês?

Parece adequado que o período em questão seja no máximo o do mês da prestação do serviço, até porque a redação do parágrafo oitavo, que será examinado mais adiante, assim dá a entender. Contudo, se seguida a lógica do contratado zero hora, generalizado em países como a Inglaterra e os Estados Unidos, o período a ser considerado poderá ser o dia, permitindo-se o pagamento imediato pelas horas.

Sobre o assunto Vólia Bomfim Cassar e Leonardo Dias Borges (2017) também entendem pela necessidade de que a máxima periodicidade a ser considerada seja a mensal, veja-se:

Poderia um empregado receber seu salário com periodicidade maior que a mensal, desrespeitando o disposto no art. 459 da CLT? O art. $4520^{\mathrm{a}}, \S 6^{\circ}$, da CLT determina que, ao 'final de cada período de trabalho', o empregado receberá o pagamento imediato da remuneração, do repouso, além das férias e trezeno proporcional. Ora, o que quer dizer 'ao final de cada período de trabalho' mencionado na lei? Poderia o professor receber no final do semestre? O motorista 'intermitente' poderia receber ao final da viagem, mesmo que esta demore dois meses? Defendemos a periodicidade máxima mensal, mesmo que o trabalho seja em período superior (CASSAR, BORGES, 2017, p. 46).

Por sua vez, o parágrafo sétimo do mesmo artigo explicita a vedação do salário complessivo, pois determina que no recibo do pagamento deverá constar a discriminação dos valores pagos relativos a cada uma das parcelas referidas no parágrafo sexto, coadunando com a Súmula 91 do Tribunal Superior do Trabalho ${ }^{3}$.

De acordo com o parágrafo oitavo o empregador efetuará o recolhimento da

\footnotetext{
${ }^{3}$ Súmula $\mathrm{n}^{\mathrm{o}} 91$ do TST. SALÁRIO COMPLESSIVO (mantida) - Res. 121/2003, DJ 19, 20 e 21.11.2003. Nula é a cláusula contratual que fixa determinada importância ou
}

contribuição previdenciária e o depósito do Fundo de Garantia do Tempo de Serviço, na forma da lei, com base nos valores pagos no período mensal e fornecerá ao empregado comprovante do cumprimento dessas obrigações. Nesse ponto, tem-se um reforço ao entendimento de que o período mencionado no parágrafo sexto seja considerado como um período mensal.

Finalmente, o parágrafo nono determina que a cada doze meses o empregado adquire direito a usufruir, nos doze meses subsequentes, um mês de férias, período no qual não poderá ser convocado para prestar serviços pelo mesmo empregador. Uma observação a ser feita neste tocante é com relação ao período de férias, que na contramão da sistemática adotada pelo texto da CLT, o período das férias aqui é disposto na fração de um mês e não de 30 dias.

Ainda nesse ponto é preciso comentar que o valor das férias acrescido do terço constitucional já foi paulatina e proporcionalmente indenizado em cada período de prestação de serviço. Destarte, o trabalhador terá direito a não ser acionado para a prestação de serviço durante o período de um mês, mas não receberá quaisquer valores quando do gozo das férias, tendo em vista que tais valores já foram devidamente indenizados de maneira proporcional ao longo dos meses de prestação de serviço.

\section{ASPECTOS SOCIAIS DO TRABALHO INTERMITENTE: VIDAS ZERO HORA}

Flávio da Costa Higa (2017), em comentários acerca do contrato de trabalho intermitente, aponta o parecer da Câmara a respeito do mesmo, bem como o parecer do expresidente do Tribunal Superior do Trabalho, Almir Pazzianotto Pinto, que de modo geral se

percentagem para atender englobadamente vários direitos legais ou contratuais do trabalhador. 
posicionaram favoráveis a essa nova modalidade de contratação, sobretudo com alegações de modernização das relações laborais e regularização do "bico". 4

Apesar desses posicionamentos, como visto, o trabalho intermitente é fruto da disseminação de um discurso em prol do flexível, do instantâneo, do pouco durável e deve ser combatido, ou ao menos adaptado a patamares civilizatórios.

A eliminação do trabalho humano, ao menos o regulado e juridicamente protegido, é um processo já em curso e que tem ganhado força. Esse discurso nega a centralidade do emprego nas sociedades contemporâneas, sustentando-se nos pilares da revolução tecnológica. Diz-se que o Direito do Trabalho, e com isso igualmente o contrato de trabalho por prazo indeterminado, está velho e precisa se modernizar para que se adéque a nova realidade social da era informacional. Oscar Ermida Uriarte adverte que (2002, p. 19):

Os fundamentos teóricos da proposta flexibilizadora são basicamente econômicos, de uma parte, e, de outra, tecnológico-produtivos, sem prejuízo da concorrência de outros fatores de origem diversa que, de uma maneira diferente, direta ou indiretamente, vêm fortalecer a referida demanda. $\mathrm{O}$ principal fundamento teórico da flexibilidade - e especialmente de sua extrema variante, a desregulamentação - assenta-se nos postulados da escola econômica neoliberal.

Ao possibilitar que o trabalhador fique a mercê das demandas imediatas do empregador,

\footnotetext{
4 'No parecer da Câmara, o 'trabalho intermitente' é apresentado sob o pálio da 'modernização sem precarização'. O documento afirma que somente essa medida poderá gerar, nos próximos 10 anos, 14 milhões de postos de trabalho, além de impactar o fomento ao primeiro emprego, à diminuição da evasão escolar e ao aumento da renda familiar. Quanto ao efeito deletério sobre os postos de trabalho existentes, Pazzianotto, ex-presidente do TST, argumenta que ela fará apenas 'a regulamentação do bico, uma realidade que já existe" (HIGA, 2017, não paginado).

5 Vólia Bomfim Cassar (2014) esclarece essa questão trabalhando as dimensões do princípio da ajenidad. Para ela “Ajenidad significa aquisição originária de trabalho por conta alheia. Este princípio revela dois conteúdos: a) que a
}

limando do contrato de trabalho a figura do tempo à disposição, o instituto jurídico do trabalho intermitente parece mitigar em limites inimagináveis o princípio da alteridade, instituto tão caro ao Direito do Trabalho. O referido princípio orienta que os riscos do empreendimento correm por conta do empregador, até porque o trabalho desempenhado pelo empregado é trabalho por conta alheia, no qual o excedente da produção não incorpora-se direta e proporcionalmente ao patrimônio do trabalhador, mas ao contrário, torna-se o lucro do empresário.

Dessa discussão inclusive surge a necessidade em refletir sobre os rumos do trabalho na sociedade brasileira e seu distanciamento do caráter forfetário da prestação dos serviços. Lembre-se que conforme disposição do art. $2^{\circ}$ da CLT (não revogado, é preciso aclarar), o trabalho nas sociedades capitalistas é revertido em benefício alheio, e exatamente por isso o empregado não pode responder pelos riscos da atividade econômica 5 .

Nesse sentido, pelo contrato intermitente, também conhecido como "contrato zero hora"6, ao permitir que o empregador faça uso da pessoa humana que trabalha apenas nos momentos que lhe convém, isto é, nas horas em que realmente exista demanda, cria-se para o empregador a

aquisição do trabalho gera o vínculo de emprego com o tomador que originariamente recebe os serviços do empregado, daí por que a aquisição é originária; b) que o trabalho é exercido para e por conta de outra pessoa. Isto quer dizer que a energia desprendida pelo trabalhador destina-se a outro que não ele próprio e que é por conta deste tomador que ele exerce seus serviços, logo, é o empregador quem corre os riscos deste negócio". (CASSAR, 2014, p. 267)

${ }^{6}$ A expressão 'contrato de zero hora' - tradução livre do artigo 27A do Employment Rights Act 1996 esclarece a sua principal característica: não há garantia de prestação de serviços e de recebimento de salário. (HIGA, 2017, não paginado). 
possibilidade de potencialização dos lucros. É o fenômeno da GIG economy ${ }^{7}$.

Mas na outra ponta, cria-se um trabalhador igualmente "zero hora" e, quiçá "zero digno", que não pode projetar sua vida, que não pode fazer quaisquer compromissos em longo prazo, que trabalha mais (exatamente por não mais poder controlar seu próprio tempo) e que por isso está mais sujeito ao adoecimento no trabalho.

A nova dinâmica do trabalho associada aos constantes riscos e a iminente falta de controle acarretam impactos sobre a vida pessoal dos trabalhadores à medida que se perde a chance e a oportunidade de organização de vida e do futuro. Até mesmo a psique do trabalhador é completamente afetada:

Os incrementos cibernéticos criam uma falsa sensação de que o trabalhador da era toyotista não mais se submete a controle de jornada nem extrapola o seu horário regular. Na verdade, os turnos são muito mais intensos, tanto pela conexão permanente do empregado com o ambiente virtual de trabalho, esteja ele em casa ou do outro lado do mundo, quanto pela existência de mecanismos eletrônicos sofisticados capazes de captar, com extrema precisão, cada passo obreiro, dentro e fora do local de trabalho. Uma das faces do perverso novo mundo laboral e da autocracia ainda marcante na relação entre o capital e o trabalho evidencia-se pelo grande número de doenças físicas e emocionais adquiridas em função do desempenho de determinadas atividades, tendo em vista, sobretudo, o poder despótico exercido pelos proprietários dos meios de produção. Como mera decorrência, as sequelas laborais passam a integrar a rotina dos operários e de tantos outros proletários, mesmo na época atual em que, equivocadamente, se apregoa a dispensabilidade do labor humano (COUTINHO, 2014, p. 54).

Em uma sociedade efêmera e instável como a atual, em que se dissemina a contratação a tempo parcial, intermitente, e sem muitas garantias em longo prazo, surgem apontamentos

\footnotetext{
7 "Ingressamos na era da chamada gig economy, na qual o trabalho se torna temporário, precário, um bico. É a intensa redução da porosidade do trabalho, pelo aproveitamento de suas sobras, do tempo 'morto' do trabalhador, que
}

de que a vida humana caminha para uma existência irracional; e mais do que nos tempos fordistas, os sujeitos caminham para um viver sem pensamento macronarrativo diante de suas vidas "zero hora". "Imaginar uma vida de impulsos momentâneos, de ação a curto prazo, despida de rotinas sustentáveis, uma vida sem hábitos, é imaginar na verdade uma existência irracional" (SENNETT, 2014, p. 50).

No novo capitalismo perde-se o aspecto do longo prazo, afetando diretamente não só a personalidade dos sujeitos, mas o caráter dos mesmos. "Diz-se que, atacando a burocracia rígida e enfatizando o risco, a flexibilidade dá às pessoas mais liberdade para moldar suas vidas" (SENNETT, 2014, p. 10). Mas apesar disso, o que se tem visto não é mais liberdade, mas ao contrário, talvez até mesmo um aprisionamento do sujeito pelo trabalho. É que para Sennett (2014, p. 10), o "novo capitalismo é um sistema de poder muitas vezes ilegível".

Conforme Sennett (2014), o que mais causa confusão no novo capitalismo é justamente o seu impacto sobre o caráter pessoal. Diferente da personalidade, para Sennett (2014) o caráter está atrelado a experiência emocional que é experimentada em longo prazo. O caráter "é o valor ético que atribuímos aos nossos próprios desejos e às nossas relações com os outros" (SENNETT, 2014, p. 10).

Nesse estado de coisas, o caráter começa a ser comprometido justamente pela substituição de tarefas permanentes por projetos e campos de trabalho, que culminam em empregos precários e temporários. É o caso do trabalho intermitente, zero hora. E assim, Richard Sennett (2014) questiona:

Como decidimos o que tem valor duradouro em nós numa sociedade impaciente, que se concentra no

normalmente estaria desperdiçado ou destinado ao lazer, repouso ou mesmo a sua qualificação". (CHAVES JÚNIOR, 2017, não paginado). 
momento imediato? Como se podem buscar metas de longo prazo numa economia dedicada ao curto prazo? Como se podem manter lealdades e compromissos mútuos em instituições que vivem se desfazendo ou sendo continuamente reprojetadas? (SENNETT, 2014, p. 10-11).

Isso não é modernização, mas como visto, tem mais a ver com a institucionalização da precariedade do trabalho e da pessoa que trabalha. Em igual sentido, segundo Flávio da Costa Higa (2017), a doutrina estrangeira acusa o contrato zero hora de ser uma máscara para o crescimento da precarização nas relações de trabalho. Exatamente por isso as experiências internacionais no uso do contrato de trabalho intermitente merecem bastante atenção:

\begin{abstract}
A experiência britânica demonstra que a nossa inquietude não é em vão. $O$ texto nacional não previne a migração de trabalhadores com contratos por prazo indeterminado para o trabalho intermitente, o que seria importante, pois o The Guardian, em 2013, revelou que 90\% dos empregados ingleses do McDonald's trabalhavam sob 'zero-hour contract.'Outra nação que merece olhares atentos é a Nova Zelândia, onde o mecanismo fora banido pelo fato de não beneficiar os trabalhadores. A partir da aprovação do Employment Relations Amendment Act 2016, os contratos de trabalho têm de especificar o mínimo de horas, os dias e os horários de trabalho (HIGA, 2017, não paginado).
\end{abstract}

De toda sorte, apesar de um diagnóstico bastante temível, não se pode vislumbrar a reforma como um fim em si mesmo. Até porque, o Direito do Trabalho brasileiro deve harmonizarse ao neoconstitucionalismo, e, portanto, toda a leitura a ser feita acerca da nova legislação do trabalho deve passar por um filtro constitucional, atenta aos fins da justiça social, vedação ao retrocesso e garantia da dignidade humana,

\footnotetext{
8 Segundo Márcio Pochmann: “Os experimentos de UBERização do trabalho avançam em forma diversificada no espaço supranacional. Começaram com iniciativas no transporte individual, por meio da desregulamentação generalizada na oferta de sistema de táxis por aplicativos das tecnologias de informação e comunicação, alcançando atualmente os contratos de zero hora, cujo trabalhador
}

preconizados pela Carta Magna. É o que adverte Jorge Luiz Souto Maior:

[...] quando se fala em direito, que fora especificamente criado, com o objetivo de inibir as injustiças provocadas pela desigualdade negocial entre trabalhadores e empresários, como ocorreu com o Direito do Trabalho, a própria sobrevivência deste direito como ramo jurídico autônomo está condicionada à preservação de seu princípio básico, qual seja a preocupação com a Justiça Social. Um direito do trabalho, que na aplicação concreta, produza resultados injustos, perde, plenamente o seu sentido (SOUTO MAIOR, 2011, p. 558).

Justamente por isso, torna-se importante considerar que diante dos malefícios dessa modalidade de contratação, o rol de direitos previstos nos incisos $\mathrm{I}$ a $\mathrm{V}$ do $\$ 6^{\circ}$ é exemplificativo, devendo os demais direitos trabalhistas ser estendidos aos empregados intermitentes (CASSAR, BORGES, 2017). E nesse sentido, aumentando-se a gama de proteção dos trabalhadores intermitentes, tem-se $\mathrm{o}$ estímulo às condições práticas e teóricas para empreender um exercício hermenêutico de resistência na tentativa de uma filtragem humanizada desse novo modelo de contratação. No presente artigo, isso será feito aventando-se a possibilidade de que a contratação intermitente seja utilizada para regularizar a prestação de serviços entre os trabalhadores e as plataformas digitais generalizadas na "era da UBERização"8.

\section{O CASO UBER E A CONTRARREFORMA: DESAFIOS E POSSIBILIDADES}

No presente estudo, observa-se que o Direito do Trabalho, ainda que em tempos de

permanece em casa aguardando a demanda de sua força de trabalho advinda de qualquer parte do mundo. Tudo isso à margem da regulação nacional de trabalho, fruto da generalização das novas tecnologias de informação e comunicação, em meio ao enorme excedente de mão-deobra (POCHMANN, 2016, p. 707). 
tentativa de sua desconstrução, pode ser compreendido como campo fértil para um exercício hermenêutico de resistência. A reforma trabalhista empreendida pela Lei 13.467, agora que se tornou realidade, deve ser aventada como um palco de novas possibilidades de proteção da classe trabalhadora, longe da precariedade que ela inicialmente aparenta intentar.

Reforça-se a necessidade de que todos os dispositivos desta nova lei sejam interpretados e aplicados tendo em vista a principiologia trabalhista e as proteções constitucionais dos trabalhadores. Exatamente por isso, ao verificarse a crise de reconhecimento da relação de emprego na "era da UBERização", em que conceitos de economia compartilhada ${ }^{9}$, dentre outros, são utilizados para mascarar os contornos do trabalho humano em plataformas digitais, deve-se agora investigar os novos institutos jurídicos trazidos pela Lei 13.467 , em especial o contrato intermitente, aventando-se a possibilidade de que essa modalidade de contratação, pelas especificidades que lhe são inerentes, seja utilizada para regularizar a prestação de serviços entre os trabalhadores e as plataformas digitais.

No presente artigo, atentos a generalização desse modelo de negócios, a empresa Uber será tomada como objeto de investigação para o teste da hipótese de que o contrato intermitente se adéqua a essa modalidade de serviços.

A empresa Uber se "auto define como uma plataforma tecnológica que, por meio de um aplicativo, para smartphones, promove o encontro entre motoristas e usuários interessados em compartilhar o uso de veículos subutilizados por seus proprietários, orientando-se pelo princípio da economia compartilhada" (TEODORO; DA SILVA; ANTONIETA, 2017, p. 2). Mas, a

\footnotetext{
${ }^{9}$ Para saber mais recomenda-se: TEODORO, Maria Cecília Máximo; DA SILVA, Thais Claudia D'Afonseca; ANTONIETA, Maria. Disrupção, economia compartilhada e o fenômeno Uber. Revista da Faculdade Mineira de Direito - PUC Minas. v. 20, n. 39, 2017.
}

despeito de ser um novo padrão de negócio, o modelo Uber parece ter vindo contaminado "de passado, com a mesma forma do antigo modo capitalista de exploração da força de trabalho, com todos os elementos fáticos-jurídicos da relação de emprego, porém com uma nova roupagem" (TEODORO; DA SILVA; ANTONIETA, 2017, p. 26).

No modelo Uber de negócios não há dúvidas de que estão presentes: o trabalho humano e personalíssimo (já que o motorista é quem presta o serviço e não pode se fazer substituir por outra pessoa utilizando-se do mesmo login), prestado em favor de outrem (Uber), que retém uma parte bastante considerável do valor que o usuário paga pela corrida. Até aqui, tem-se presentes os elementos: pessoa física, pessoalidade e onerosidade.

Os dois elementos que suscitam maiores controvérsias e que têm sido comumente utilizados para impedir a configuração do vínculo empregatício são a subordinação e a habitualidade. Parece que a figura da contratação intermitente dá conta de solucionar essas questões, possibilitando uma contrarreforma da reforma, no intuito de regularizar a prestação de serviços entre os motoristas e a plataforma digital.

No modelo Uber de negócios, no tocante a subordinação, são combinados os meios pessoais com os meios telemáticos de comando, controle e supervisão do trabalho. $\mathrm{O}$ motorista recebe ordens de adequação de conduta (fornecer água, balas, regular o som automotivo de acordo com as preferências do cliente, dentre outras). A avaliação do serviço é terceirizada para o cliente, que determina o score do motorista, que é sancionado pela Uber caso tenha reiteradas baixas avaliações ${ }^{10}$.

10 “O Uber, assim como outras empresas que operam com a mesma lógica, estabelece regras, critérios de avaliação, métodos de vigilância sobre o trabalhador e seu trabalho, ao mesmo tempo que se exime de responsabilidades e de exigências que poderiam configurar um vínculo 
Ainda no tocante a subordinação, importante considerar que o motorista prestador de serviço não possui qualquer ingerência sobre o preço/tarifa a ser cobrada pelo serviço, estando adstrito ao que o aplicativo determina. Hoje, sabese que as plataformas também estabelecem metas e oferecem bonificações em caso de cumprimento.

O motorista, caso logado à plataforma, não pode recusar as corridas que não deseja, sob pena de sanções disciplinares. Da mesma forma, o motorista está proibido de estabelecer corridas de transporte "por fora" do aplicativo, sendo dele exigida exclusividade e também sendo dele exigido que faça a rota determinada pelo aplicativo. A rota é completamente controlada pelos algoritmos do sistema.

Nesse sentido, a subordinação parece clara, até mesmo porque o art. $6^{\circ}$, parágrafo único, da CLT, estabelece que "os meios telemáticos e informatizados de comando, controle e supervisão se equiparam para fins de subordinação jurídica, aos meios pessoais e diretos de comando, controle e supervisão do trabalho alheio". Logo, não é preciso ir longe para detectar a presença da subordinação.

Com relação à habitualidade, a depender de cada caso, torna-se bastante possível dizer que o trabalho não é eventual, na medida em que possua caráter de permanência, dando vistas a continuidade da prestação do serviço, e afastando as características que possibilitariam a configuração do trabalho esporádico (TEODORO; DA SILVA; ANTONIETA, 2017).

Apesar disso, a suposta faculdade do trabalhador se conectar ao aplicativo nos dias e horários que lhe sejam convenientes, isto é, estabelecer sua própria jornada, tem sido utilizada

empregatício. Consumo, avaliação, coleta de dados e vigilância são elementos inseparáveis. Em realidade, o controle sobre o trabalho é transferido para a multidão de consumidores, que avaliam os profissionais a cada serviço demandado. Essa avaliação fica visível para cada usuário que for acessar o serviço com aquele trabalhador. A como argumento para afastar o elemento da subordinação e também da habitualidade.

Inicialmente, é preciso esclarecer que a jornada nunca foi elemento fático-jurídico da relação de emprego, mas elemento natural do contrato de trabalho. Além disso, a faculdade da conexão não passa de uma alegação, pois, sabidamente, caso o motorista fique um longo período de tempo sem se conectar ao aplicativo ele será banido do sistema e impedido de realizar novas corridas. E ainda que não o fosse, conforme disposto no art. 452-A, $\S 3^{\circ}$ da CLT, com redação dada pela Lei 13.467/2017, o contrato de trabalho intermitente agora permite dizer que a recusa da oferta de trabalho por parte do empregado não descaracteriza a subordinação.

Logo, em um simples exercício interpretativo, torna-se possível dizer que não há mais justificativas para o não reconhecimento do vínculo de emprego entre os trabalhadores e as plataformas virtuais do modelo Uber de serviços, pois a própria lei possibilita agora ao trabalhador recusar a oferta de trabalho (no caso Uber a conexão sistemática à plataforma), sem que isso desconfigure a subordinação. E lado outro, ao prever que será considerado como intermitente o contrato de trabalho no qual a prestação de serviços, com subordinação, não é contínua, ocorrendo com alternância de períodos de prestação de serviços e de inatividade, determinados em horas, dias ou meses, não há mais como se cogitar o afastamento da relação de emprego no presente caso, pois, conforme já aventado, nesse tipo de contrato os artigos $443, \S$ $3^{\circ}$ e $452-B$ parece obliterarem a habitualidade como elemento da relação de emprego.

Importante ressaltar que mesmo que a exigência de o chamado para o trabalho no

certificação sobre o trabalho vem agora da esfera do consumo, por meio dessa espécie de gerente coletivo que fiscaliza permanentemente o trabalhador. A multidão vigilante, na forma multidão, é então quem garante de forma dispersa a certificação sobre o trabalho" (ABÍLIO, 2017, não paginado). 
contrato intermitente ser de 3 dias, no mínimo, se o empregado aceitar imediatamente esta norma não resta prejudicada, o que torna possível confirmar que o trabalhador de plataformas virtuais agora se enquadra perfeitamente na figura jurídica do trabalho intermitente. Nesse diapasão, tendo em vista que o ônus da forma é do empregador, tem-se, por óbvio, que as plataformas, desde o dia 11 de novembro de 2017, data em que a Lei 13.467 entrou em vigor, deveriam se adequar a essa nova realidade de contrato, com todos os requisitos que lhe são inerentes.

Isto é, o contrato de trabalho intermitente deve ser celebrado por escrito e deve conter especificamente o valor da hora de trabalho, que não pode ser inferior ao valor horário do salário mínimo ou àquele devido aos demais empregados do estabelecimento que exerçam a mesma função em contrato intermitente ou não, sob pena de que além de reconhecido o vínculo de emprego, seja também reconhecida a indeterminação do contrato. Afinal, por ser modalidade excepcional de contratação, o contrato de trabalho intermitente demanda a observância de todos os requisitos formais por parte do empregador, que detém o ônus da forma.

\section{CONCLUSÃO}

Ao analisarmos a reforma trabalhista, em especial a nova figura jurídica do contrato intermitente, verifica-se a possibilidade de uma verdadeira hermenêutica de resistência, que se utilizando das próprias peculiaridades desse novo modelo de contratação, torna possível ampliar a gama de proteção do Direito do Trabalho na contemporaneidade.

O contrato de trabalho intermitente é um contrato que altera significativamente o modo como têm sido pensados os cinco elementos fático-jurídicos da relação de emprego, sobretudo no que tange ao elemento da habitualidade ou não-eventualidade e até mesmo o da subordinação. Não é um contrato que deve ser exaltado como uma benesse para a sociedade brasileira. Lembremos das experiências internacionais que demonstraram cabalmente a perniciosidade de adoção desse modelo, tanto que em muitos países ele não se generalizou.

O contrato de trabalho intermitente não tem muito a ver com a modernização alegada pelos legisladores da reforma trabalhista, ao contrário, tem mais a ver com a institucionalização da precariedade do trabalho e da pessoa que trabalha. O contrato de trabalho intermitente balança os fundamentos do Direito do Trabalho em vários aspectos.

Ao permitir que o empregador faça uso da pessoa humana que trabalha apenas nos momentos que lhe convém, isto é, nas horas em que realmente exista demanda, cria-se para o empregador a possibilidade de potencialização dos lucros, mas na outra ponta, cria-se um trabalhador igualmente "zero hora", que não pode projetar sua vida, que não pode fazer quaisquer compromissos em longo prazo, que não controla seu próprio tempo e trabalha mais e que por isso está mais sujeito ao adoecimento no trabalho.

Mas, tal diagnóstico não pode ser fatalista. Observamos que o Direito do Trabalho, ainda que em tempos de desconstrução, pode ser compreendido como campo fértil para um exercício hermenêutico de resistência. A reforma trabalhista empreendida pela Lei 13.467, agora que se tornou realidade, deve ser aventada como um palco de novas possibilidades de proteção da classe trabalhadora, longe da precariedade que ela inicialmente aparenta intentar. É um trabalho que exige grande esforço dos pensadores do Direito, mas que deve ser empreendido em prol das garantias constitucionais da classe trabalhadora.

Ao identificarmos a crise de reconhecimento da relação de emprego na "era da UBERização", em que conceitos de economia compartilhada, dentre outros, são utilizados para 
mascarar os contornos do trabalho humano em plataformas digitais, deve-se agora investigar os novos institutos jurídicos trazidos pela Lei 13.467, em especial o contrato intermitente, aventando-se a possibilidade de que essa modalidade de contratação, pelas especificidades que lhe são inerentes, seja utilizada para regularizar a prestação de serviços entre os motoristas e a plataforma digital. Pelas disposições dos artigos 443 e 452-A, da CLT, com redação dada pela Lei 13.467 , o contrato de trabalho intermitente agora nos permite dizer que boa parte dos trabalhadores de plataformas virtuais que hoje se encontram na informalidade, deverão ser juridicamente protegidos pela ciência justrabalhista.

\section{REFERÊNCIAS}

ABÍLIO, Ludmila Costhek. Uberização do trabalho: subsunção real da viração. Publicado em 22/02/2017. Disponível em: < https://blogdaboitempo.com.br/2017/02/22/uberizacao-do-trabalhosubsuncao-real-da-viracao/>. Acesso em: 02 out. 2017.

BRASIL. DECRETO-LEI N. ${ }^{\circ}$ 5.452, DE $1^{\circ}$ DE MAIO DE 1943. Aprova a Consolidação das Leis do Trabalho. Disponível em: 〈http://www.planalto.gov.br/ccivil_03/decreto-lei/Del5452.htm>. Acesso em: 01 de out. 2017.

LEI $N^{\circ}$ 13.467, DE 13 DE JULHO DE 2017. Altera a Consolidação das Leis do Trabalho (CLT), aprovada pelo Decreto-Lei no 5.452, de 1o de maio de 1943, e as Leis nos 6.019, de 3 de janeiro de 1974, 8.036, de 11 de maio de 1990, e 8.212, de 24 de julho de 1991, a fim de adequar a legislação às novas relações de trabalho. Disponível em: <http://www.planalto.gov.br/ccivil_03/_Ato20152018/2017/Lei/L13467.htm>. Acesso em: 30 set. 2017.

Tribunal Superior do Trabalho. Súmula $n^{o} 91$ do TST. Disponível em: < http://www3.tst.jus.br/jurisprudencia/Sumulas_com_indice/Sumulas_Ind_51_100.html\#SUM-91>. Acesso em: 03 out. 2017.

CASSAR, Vólia Bomfim; BORGES, Leonardo Dias. Comentários à Reforma Trabalhista: Lei 13.467 de 13 de Julho de 2017. Rio de Janeiro: Forense; São Paulo: Método, 2017.

CASSAR, Vólia Bomfim. Direito do Trabalho. 9 ed. São Paulo: Método, 2014.

CHAVES JÚNIOR, José Eduardo de Resende. O Direito do Trabalho Pós-Material: o contrato realidade-virtual da «multidão» produtora. 2017. Disponível em: <http://emporiododireito.com.br/odireito-do-trabalho-pos-material/>. Acesso em: 02 out. 2017.

COUTINHO, Grijalbo Fernandes. Terceirização e Acidentalidade (Morbidez) no Trabalho:uma estreita relação que dilacera a dignidade humana e desafia o Direito. Dissertação apresentada ao Programa de Pós-Graduação em Direito da Faculdade de Direito da Universidade Federal de Minas Gerais como requisito parcial para a obtenção do título de mestre. Belo Horizonte, setembro de 2014. Disponível em: < http://www.bibliotecadigital.ufmg.br/dspace/bitstream/handle/1843/BUBD9ZCNXB/disserta_o_grijalbo_fdufmg_29.09.2014.pdf?sequence=1>. Acesso em: 05 out. 2017.

HIGA, Flávio da Costa. Reforma trabalhista e contrato de trabalho intermitente. Revista Consultor Jurídico, 8 de junho de 2017. Disponível em: < http://www.conjur.com.br/2017-jun-08/flavio-higareforma-trabalhista-contrato-trabalho-intermitente>. Acesso em: 03 out. 2017. 
POCHMANN, Márcio. A crise capitalista e os desafios dos trabalhadores. Cadernos do CEAS, Salvador, n. 239, 2016.

PORTUGAL. LEI N. ${ }^{\circ}$ 7/2009 DE 12 DE FEVEREIRO. Aprova a revisão do Código do Trabalho. Disponível em: <http://cite.gov.pt/asstscite/downloads/legislacao/CT25092017.pdf\#page=64>. Acesso em: 03 out. 2017.

SENNETT, Richard. A corrosão do caráter: as conseqüências pessoais do trabalho no novo capitalismo. Tradução: Marcos Santarrita. 18ª Ed. Rio de Janeiro: Record, 2014.

SOUTO MAIOR, Jorge Luiz. Curso de Direito do Trabalho - Teoria Geral do Direito do Trabalho Volume I Parte I. LTR, 2011.

Sem uma seção especial de justiça para a "reforma trabalhista". Revista eletrônica [do] Tribunal Regional do Trabalho da 9a Região, Curitiba, PR, v. 6, n. 61, p. 182-189, jul./ago. 2017.

SOUTO MAIOR, Jorge Luiz; SEVERO, Valdete Souto. Os 201 ataques da "reforma" aos trabalhadores. 08 mai. 2017. Disponível em: <http://www.jorgesoutomaior.com/blog/os-201ataques-da-reforma-aos-trabalhadores>. Acesso em 04 out. 2017.

TEODORO, Maria Cecília Máximo; DA SILVA, Thais Claudia D'Afonseca; ANTONIETA, Maria. Disrupção, economia compartilhada e o fenômeno Uber. Revista da Faculdade Mineira de Direito PUC Minas. v. 20, n. 39, 2017.

URIARTE, Orcar Ermida. A Flexibilidade. Tradução: Edilson Alkmim Cunha. Editora: LTR - São Paulo, 2002. 
